\title{
Studies of Osteoporosis in Cancer Patients in Slovakia - Experience from Single Institute
}

\author{
Beata Spanikova and Stanislav Spanik \\ St. Elisabeth Cancer Institute, Bratislava \\ Slovak Republic
}

\section{Introduction}

Osteoporosis is a metabolic skeletal disease characterized by low bone mineral density (BMD), damage of bone microstructure, bone fragility resulting in increase risk of bone fractures. Epidemiologic data are continuously showing rising number of newly diagnostic patients with osteoporosis. The expected number of bone fractures due to osteoporosis is to be 6.26 million in 2050, growth from 1.56 million in 1990 (Payer et al., 2007). The fractures are usually localized in lumbar spine (or other vertebra), hip and forearm (wrist), The most serious is the fracture of proximal femur (hip), beacuse approximately $20 \%$ of these pateints die within one year after the fracture and almost $80 \%$ become dependent on some kind of care (Cooper, 1997). The precise number of vertebral pathological fractures is difficult to assess, because many of these fractures are asymptomatic. Despite this they increase mortality by $23 \%$ (Cooper, 2007). The wrist fracture do not increase the mortality. The incidence is much more frequent in women than in men $(4: 1)$. The increased frequency of osteoporosis is partly due to increase in absolute number of new patients and partly due to continualy improving diagnostic procedures. The new generation of equipments and laboratory technics more precisely identify patients with bone loss. In the same time improvement in public information leads to increasing number of densitometric examinations.

Bone tissue is highly active metabolic organ. The bone tissue remodelation (formation of new bone tissue and its degradation) is active and continual process. Very important role in regulation of this process have hormones (estrogens and androgens). The mostly understood and resolved is postmenopausal osteoporosis and the most important risk groups and factors were identified (Rizzoli et al., 2005).

Cancer patients, especially those with "hormone dependent" disease (breast cancer, prostate cancer) or those with treatment interfering in hormonal metabolism (breast cancer, prostate cancer, thyroid cancer, ovarian cancer, germ cell tumor and others) are in inceased risk of disease or therapy induced osteoporosis. There are increased numbers of information and references on this topic.

The most advanced are data on patients with breast cancer, particularly those with early breast cancer (EBC) on adjuvant aromatase inhibitors (AI) therapy.

Women with breast cancer, especially those receiving aromatase inhibitors are at higher risk for bone loss and fracture. Postmenopausal women may already have multiple risk factors 
for fracture, and breast cancer therapies compound these risk (Hadji \& Bundred, 2007). Fractures can have serious clinical consequences including need for major surgery, increased morbidity and mortality, increased cost of disease management, and reduced quality of the life for patients (Body, 2011).

Additional group of patients in risk are those with prostate cancer on hormonal therapy, thyroid cancer (TC) after total or nearly total thyroidectomy on whole-life substitution therapy by oral thyroxine $\left(\mathrm{T}_{4}\right)$ and patients with germ cell tumors (GCT) after surgery and radiotherapy and/or chemotherapy.

We have started to measure BMD in patients with breast cancer (BC), prostate cancer, thyroid cancer (TC) and germ cell tumors few years ago. Some of the results are nearly mature and ready to be publish (EBC, TC, GCT) others need more patients and time of follow-up (PC).

\section{Breast cancer}

\subsection{Introduction}

Postmenopausal breast cancer patients are in high risk of osteoporosis in many reasons primary diagnosis of breast cancer, then side-effects of anticancer therapy, postmenopausal status. These factors mean not just elevated risk of bone loss, osteoporosis, but especially risk of patological fractures. Many of postmenopausal breast cancer patients, especially those with early stage, with aromatase inhibitors (AI) adjuvant therapy have very good prognosis. The elevated risk of osteoporosis can lead to patological fractures which may markedly worsen their quality of life (Coleman et al., 2008).

Antagonizing estrogen in hormone-dependent breast cancer is well-known method of reducing tumor growth. Five years of treatment with tamoxifen, an antiestrogen or selective estrogen-receptor modulator (SERM), has been shown to reduce the risk of recurrence and breast cancer mortality by $41 \%$ and $34 \%$ respectively and is still recommended as one of several options for early-stage hormone receptor-positive breast cancer.

New data from clinical trials comparing third-generation aromatase inhibitors (AI) with tamoxifen have confirmed that AI offer significant efficacy and tolerability advantage over tamoxifen. Aromatase inhibitors are recommended as adjuvant treatmen for postmenopausal women with hormone-receptor positive early breast cancer. The group of clinicaly used AI contains non-steroidal AI letrozole and anastrozole and steroidal-AI exemestane. The primary mechanism of action of AI is inhibition of aromatase activity. Aromatase is the most important enzyme responsible for conversion of androgens to estrogens, mainly in tissues outside endocrine system. This is the most important mechanism of estrogen production in postmenopausal women. Estrogen production blockade influences bone metabolism directly via osteoclastogenesis stimulation. Survival extension of osteoclasts is the main mechanism. Cytokines, interleukines 1 and 6, osteoprotegerin, bone resorption potentiation, osteocytes and osteoblasts apoptosis are other important mechanisms resulting in osteosynthesis inhibiton. AIs also play key role in calcium metabolism. Their action influence calcium absorption in small bowel and renal elimination. It is very similar to estrogens level decrease after menopause leading to postmenopausal osteoporosis (Rizzoli, 2005).

AIs in breast cancer treatment are used as adjuvant therapy - it means after radical surgery in early breast cancer, stages I - III or as palliative therapy of locally advanced or metastatic disease. Standard duration of adjuvant hormonal therapy is now 5 years. Recently 
published results of large international multicenter clinical studies (including more than 15 000 pacients) such as ATAC (Howell et al., 2005) and BIG (Coates et al., 2007) have shown that adjuvant hormonal therapy using AIs and lasting 5 years is more effective than adjuvant therapy using selective estrogen receptor modulators (SERMs), mainly tamoxifen. Substudies of these and many other similar studies dealing with bone mineral density (BMD) in early breast cancer patients on adjuvant hormonal therapy are consistently showing higher decrease of BMD during treatment with AIs than that with tamoxifen. This is the reason why regular BMD measurements at the beginning and during AIs adjuvant therapy were implemented into new recommendations for early breast cancer therapy published in July 2007 as results of consensus of panel of most important international leaders in the field during 10 $10^{\text {th }}$ St Gallen Conference (Goldhirsch et al., 2007).

\subsection{Patients and methods}

We started regular bone mineral density (BMD) measurement of postmenopausal early breast cancer patients treated either with aromatase inhibitors (AIs) or tamoxifen in St. Elisabeth Cancer Institute on September 2005. The most important goal of our study was to determine bone mineral density decrease in early breast cancer patients treated with (AIs). We measured BMD at the begining of treatment and during therapy (after one year or two depending on initial results) with AIs and a group of patients who have their hormonal therapy switched from tamoxifen do AIs for different reasons (intolerance or toxicity).

As an comparative groups we measured BMD in group of early breast cancer patients treated with tamoxifen and patients after finished hormonal therapy without any anticaner therapy, only on regular follow-up. The study is sitll active, in this preliminary evaluation we analysed group of 263 consecutive patients with early breast cancer, 42 on active AIs therapy - 22 on letrozole on oral daily dose $2,5 \mathrm{mg}, 20$ on anastrozole on oral daily dose 1 mg, 72 patients with "switched" therapy from tamoxifen to AIs, 69 on active tamoxife therapy on oral daily dose $20 \mathrm{mg}$ and 80 patients just on follow-up after finishing active hormonal treatment.

In all our patients the BMD measurement was performed on total body densitometer Hologic Explorer. We measured and evaluated region of proximal femur and L spine. In cases of degenerative changes which overestimated results we measured and evaluated the region of forearm. For comparisons we evaluated T score. All patients included in our study have measured height, weight, assessed age, duration of menopause, hormonal replacement therapy and history of other risk factors and previous fractures. All patients have measured calcium blood level. We also measured markers of bone turnover, CTX (CrossLaps - C telopeptide of alfa chain 2(I) colagen) as marker of osteoporosis measured by ELISA method and isoensyme of ALP as marker of osteoproduction. In patients with BMD results on levels of osteoporosis we made differential diagnostic examinations to exclude secondary osteoporosis. This is important especially in patients with breast cancer to exclude bone marrow metastases, which are most frequent sites of generalised disease. We used cancer markers, RTG, CT, MRI or bone scan - sceletal gamagraphy

For the statistical analysis we used standard methods of descriptive statistics, test of data independence and multiple regression was used to verify influence of separate factors especially to exclude possible secondary influences in case of interactive correlation among parameters. 


\subsection{Results}

From the whole study group of 263 postmenopausal early breast cancer patients, 114 patients in the group treated with AIs (72 of them switched from previous tamoxifen to AIs), 69 on tamoxifen therapy and 80 patients without hormonal therapy only on follow-up after finishing hormonal treatment (figure 1).

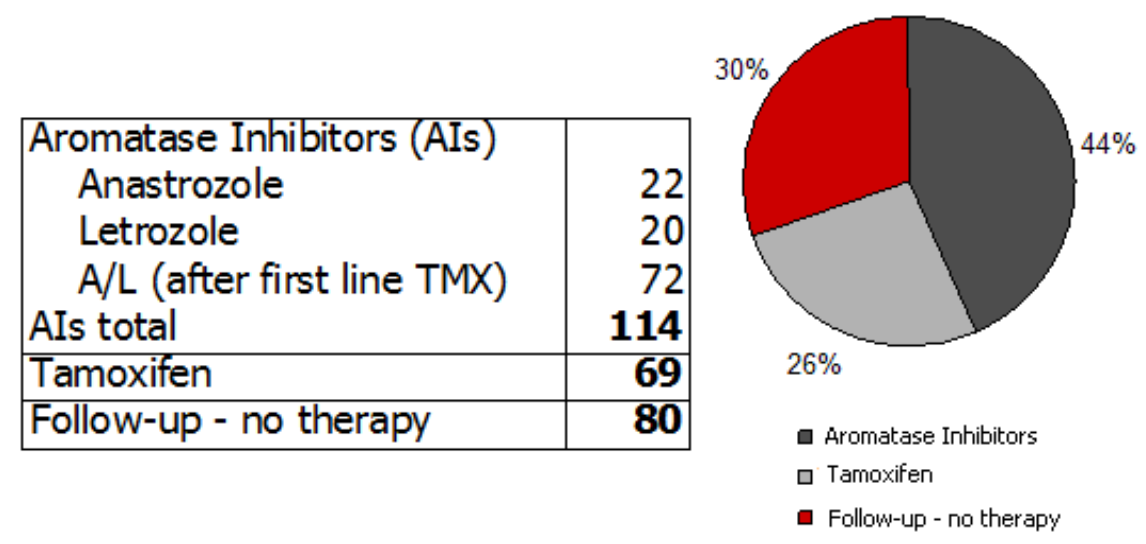

Fig. 1. Patients Characteristics

We found normal BMD only in 13,31\% among all evaluated patients, 43,35\% of the whole analysed patients had BMD rate in levels of osteoporosis. Analysing the localisations of measured osteoporosis we found this in 5,25\% in proximal femur, 63,1\% in L spine and $31,58 \%$ in region of the forearm (figure 2) - those were patients with deformations or degenerative changes in region of spine, which overestimated the results.

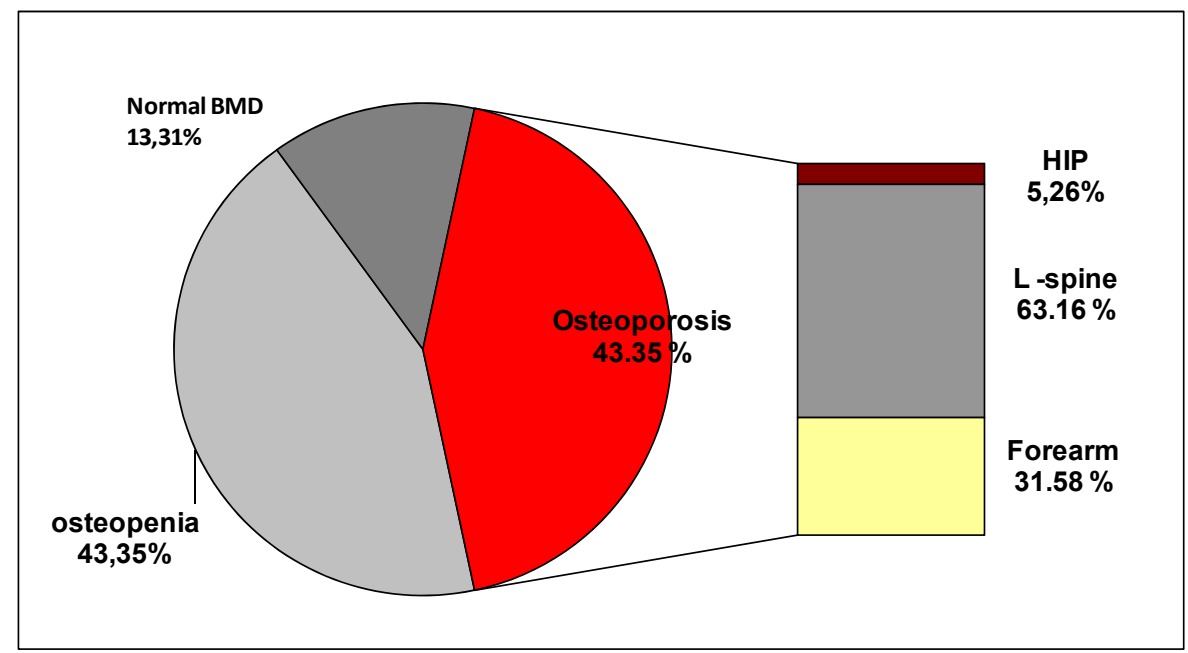

Fig. 2. BMD in Patients with Breast Cancer 
Median of age of the whole group of patients was 61 years. The BMD loss to levels of osteoporosis was found in group of patients under 50 years of age in $26 \%$, where $50 \%$ of them had osteoporosis in region of L spine, $38 \%$ in region of proximal femur and only $13 \%$ in region of forearm. The rate of osteoporosis was higher in the group of patients older than 70 years - $73 \%$ and most of them had osteoporosis in the region of forearm $-49 \%$. The region of $\mathrm{L}$ spine was overestimated by degenerative and deformative changes in this age group of patients. Group of patients in age between 50 to 70 years had BMD levels of osteoporosis in $34 \%$, most frequently in region of L spine $-80 \%$. These findings are in correlation with many clinical studies confirming rising incidence of osteoporosis with rising age. We confirm influence of menopause duration on osteoporosis as well as negative correlation of weight and osteoporosis in our study. All this findings are in consensus with literature data.

We also analysed impact of therapy on BMD loss. In the group of patients with AI therapy BMD loss to level of osteoporosis was diagnosed in $43,86 \%$ and normal BMD had $13,16 \%$ of patients, in the group with tamoxifen therapy the rate of osteoporosis was $30,43 \%$ and normal BMD had $18,84 \%$ of patients, in the group on follow-up without hormonal therapy the rate of osteoporosis was $53,75 \%$ and normal BMD had $8,7 \%$ of patients. The correlation between BMD loss and hormonal therapy was not proven statistically significant despite trend of tamoxifen protective effect on BMD maintenance. This was not statistically significant - $(\mathrm{p}=0,0610)$. In subanalysis, where we correlate BMD loss only in subgroup of patients treated by AIs at least one year and patients treated less than 1 year or just on follow-up without hormonal therapy (figure 3), the difference was statistically significant. The rate of BMD loss to level of osteoporosis was $53,13 \%$ in the first group and only $40,2 \%$ in the letter and normal BMD rate was only $3,13 \%$ in the first group versus $16,58 \%$ in second one - $(p=0,0150)$.

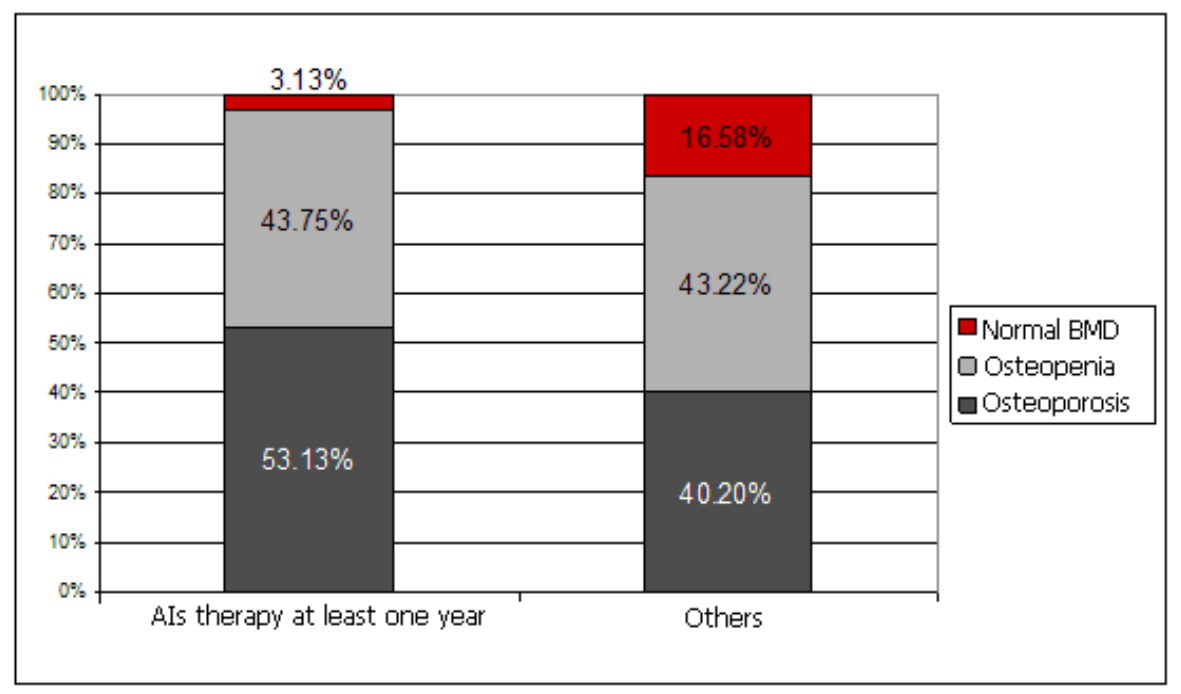

Fig. 3. BMD in Patients with Aromatase Inhibitors Therapy and Others 
We analysed other risk factors and we found highest rate of patients with diabetes mellitus among those risk factors (33 patients) but we did not confirm statistical significant influence of diabetes mellitus on BMD loss - $(\mathrm{p}=0,816)$.

Correlation of BMD loss and increase levels of CTX as a marker of bone resorption was not confirmed in our study.

We tested all above mentioned risk factors statistically also (figure 4) using method of multiple linear regression to eliminate potential secondary influences in cross interactions among factors. Correlations BMD level to age $(p<0,0001$ and weight $(p<0,0001)$ were confirmed by multiple linear regression. Borderline statistical significance was shown in correlation to AIs therapy $(=0,0476)$. The influence of time from menopause $(p=0,3410)$ seemed to be secondary regarding to high correlation to age of patients $(r=0,89, p<0,0001)$.
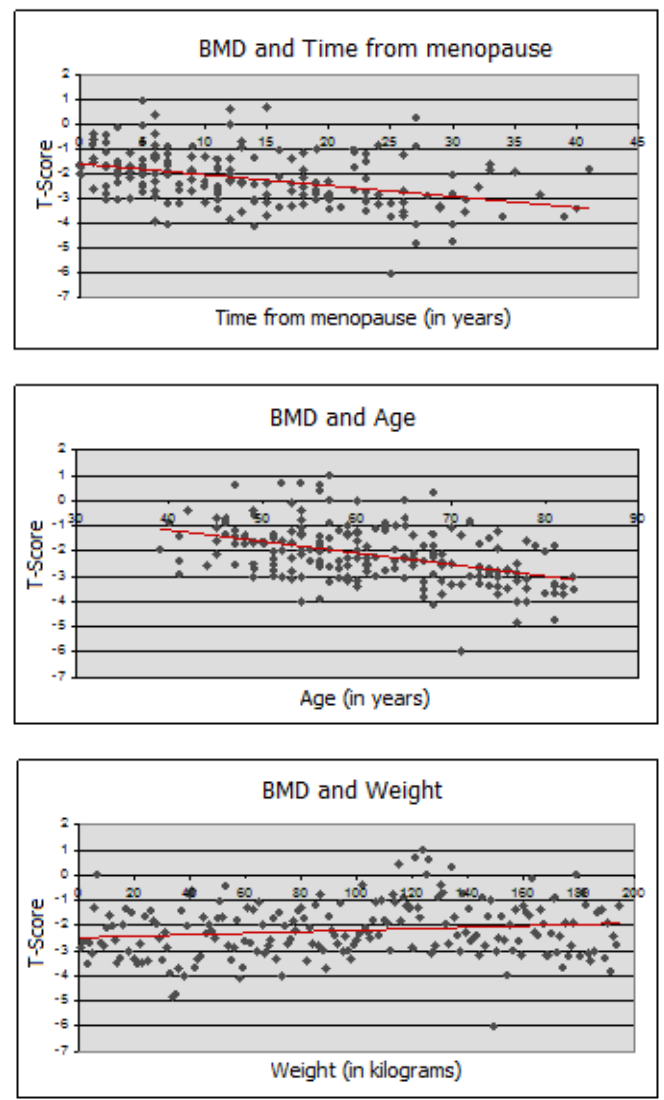

Correlation coefficients:

$($ BMD,Age $)=-0.44(p<0.001)$

(BMD, Weight $)=0.43(p<0.001)$

(BMD, Time from menopause $)=-0.39(p<0.001)$

Fig. 4. Correlation of BMD with Age, Weight and Time from Menopause 
The rate of pathological fractures was analysed also (figure 5). The most frequent incidence was in group of patients with osteoporosis. Wrist fracture was found in 10 patients and 5 had fractures in region of L spine. In the group of patients with BMD on level of osteopenia, 5 patients had pathological fractures, 3 of them were wrist fractures and 2 in region of $L$ spine. There were only 2 pathological fractures in patients with normal BMD levels, both were wrist fractures. The whole group of patients we considered to be too small to make statistical analysis of risk factors of pathological fractures.

The last was the analysis of influence of antiresorptive therapy on BMD changes (figure 6). The analysis seemed to be preliminary as in the control group (control BMD measurement after 1 year of duration of antiresorptive therapy) were only 53 patients. This did not allow us to make relevant statistical analysis, although we found trend toward protective effect of antiresorptive therapy in this group of patients.

\begin{tabular}{|c|r|}
\hline Osteoporosis \\
\hline Wrist \\
Spine & 10 \\
Hip & 5 \\
\hline Osteopenia & 0 \\
\hline Wrist & 3 \\
Spine & 2 \\
Hip & 0 \\
\hline Normal BMD & \\
\hline Wrist & 2 \\
Spine & 0 \\
Hip & 0 \\
\hline
\end{tabular}

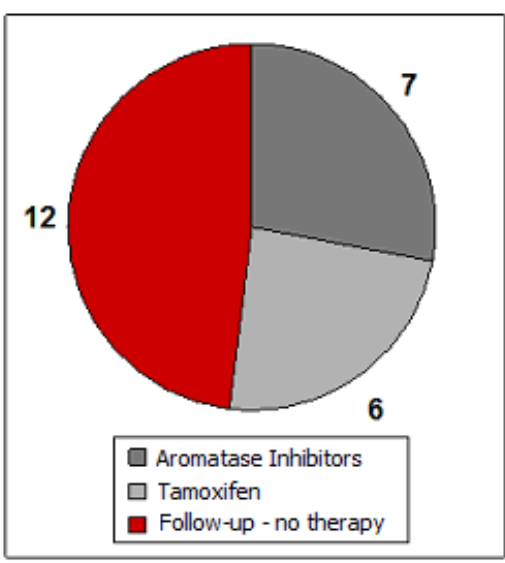

Fig. 5. Patological Fractures Rate

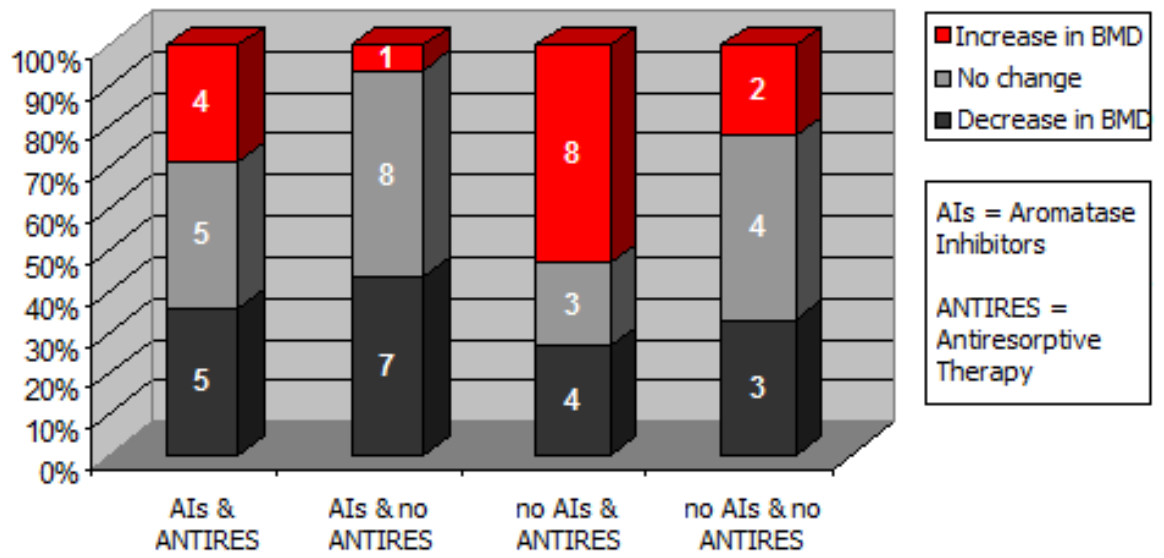

Fig. 6. Impact of Antiresorptive Therapy on BMD in patients with Breast Cancer 


\subsection{Discussion}

The AIs are new standard in adjuvant hormonal therapy of early breast cancer postmenopausal patients. As the results of many large international multicentre clinical trials are more mature and results of substudies focused on BMD loss more and more consistant, new standards for BMD examination are evolving. The prognosis of early breast cancer patients is continually improving. BMD loss means increasing risk of osteoporosis and it means increasing risk of pathological fractures. There are many risks factors for this group of patients - age, postmenopausal status, breast cancer, AIs therapy. Adjuvant hormonal therapy is one of the most important factors leading to significant improvement in patient survival and the same important is quality of life which may be markedly decreased by pathological fractures from osteoporosis.

Identification of all risk factors of origin and progression of osteoporosis as well as exact examination procedures to find them is as important as prevention and therapy of BMD loss. Generally confirmed risk factors for pathological fractures of osteoporosis in breast cancer patients are:

\begin{tabular}{|l|}
\hline AIs therapy \\
\hline T-score $<1.5$ \\
\hline Age $>65$ years \\
\hline Low body mass index $\left(\mathrm{BMI}<20 \mathrm{~kg} / \mathrm{m}^{2}\right)$ \\
\hline Family history of hip fracture \\
\hline Personal history of fracture from osteoporosis after age of 50 \\
\hline Oral corticosteroid therapy lasting $>6$ months \\
\hline Smoking (in present or in past) \\
\hline
\end{tabular}

Table 1. Risk factors for pathological fractures of osteoporosis in breast cancer patients

In multicenter international clinical trial "ATAC", where the postmenopausal early breast cancer patients were randomised (final design) to AI anastrozole (A) versus tamoxifen (T) showed that after 5 years of therapy (Howell et al., 2005) there were significantly more bone fractures on arm A (11\% versus 7\%; p < 0. 001). In clinical trial „BIG 1-98“ the same postmenopausal early breast cancer patients were randomised to AI letrozole (L) versus tamoxifen (T). With median of follow-up of 26 months (Thurliman et al., 2005) there were significantly more bone fractures on arm $\mathrm{L}(5.7 \%$ versus $4.0 \% ; \mathrm{p}<0.001)$. Very similar results were reached in the clinical study "IES“ where the postmenopausal early breast cancer patients were randomised to AI exemestane (E) versus tamoxifen (T) and with median of follow-up 56 months (Coombes et al., 2007) there were significantly more bone fractures on arm E (7\% versus $4.9 \% ; p=0.003)$. In combined clinical study "ABCSG-8 and ARNO 95" the patients were "switched" after anastrozole (A) therapy to tamoxifen (T) vs continuing $\mathrm{T}$ therapy. With median of follow-up of 28 months (Jakesz et al., 2005) there was similar significant difference against arm A $(2 \%$ versus $1 \% ; p=0$. 015). In the clinical study "MA.17“ were the patients after 5 years on tamoxifen (T) therapy randomised to "switch" to anastrozole (A) versus only follow-up without 
hormonal treatment. With median of follow-up of 30 months (Goss et al., 2005), there were more patients with newly diagnostic osteoporosis on arm A $(8.1 \%$ versus $6.0 \%$; $=$ 0. 003), and more bone fractures (5. $6 \%$ versus $4.6 \%$, this difference was however not statistically significant $p=0.25$ ).

In comparison of patients on AI anastrozole (A) therapy from the clinical study "ATAC" to their healthy counterparts matched in age, postmenopausal status, with osteopenia, the incidence of bone fractures were nearly doubled.

We confirmed the prognostic importance of age, duration of menopause, AIs treatment in comparison to tamoxifen treatment or no therapy in follow-up group in our clinical observation. All these results are in concordance with world scientific literature.

According to WHO and NOF (National Osteoporotic Foundation) guidelines is the value of T-score in BMD measurement critical in distribution to normal BMD (T-score $\geq-1$. 0 ), osteopenia (T-score between - 1.0 and - 2. 5) and osteoporosis (T-score $\leq-2.5$ ) (Kanis et al., 2008). According to international general guidelines is this classification universally accepted and it is recognised that with decreasing BMD level the risk of pathological bone fractures is rising. That is why the results and observations of the clinical study NORA (National Osteoporosis Risk Assessment) are so interesting. They observed > 200000 healthy postmenopausal women and found that $82 \%$ pathological bone fractures happened in women with T-score $>-2$. 5, which means that they did no have osteoporosis and $52 \%$ fractures were in women with osteopenia (T-score - 1. 0 to - 2.5).

All these results and findings confirm the importance of BMD measurement before AIs therapy initiation and importance of preventive measurements as components of adjuvant AIs therapy as well. Calcium and vitamin D supplementation and appropriate physical activity are standard components of these recommendations (Goldhirsch et al., 2007). Preventive bisphosphonates application is being evaluated in many running clinical studies. Especially zoledronic acid is showing excellent results and it seems to be incorporated into standard combination with AIs in adjuvant therapy of postmenopausal early breast cancer patients very soon as osteoporosis and bone fracture prevention (Gnant et al., 2007).

There was observed protective effect against bone loss, longer period to bone metastases occurence and suspected direct anticancer effect as well. These results will probably lead very soon to change today 's standards and bisphosphonates will be used together with AIs in adjuvant therapy of early breast cancer patients (Gnant et al., 2007).

The influence of antiresorptive therapy on BMD was part of our study as well. This analysis is difficult to interpret as our control group (control BMD measurement after 1 year of duration of antiresorptive therapy) was very small (only 53 patients) and median of followup very short. This did not allow us to make relevant statistical analysis but we found trend toward protective effect of antiresorptive therapy in this group of patients.

We did not confirm correlation of BMD decrease and CTX elevation. Probably the reason was small analysed group of patients and low specificity of CTX as osteoporosis marker (S.Špánik \& B. Špániková, 2010).

\subsection{Conclusions and future directions}

The most important goal of our study was to confirm the importance of BMD measurement and evaluation in group of postmenopausal early breast cancer patients on AIs therapy. Even the study group is not very large, all the patients are from single 
institute and we have planned to follow-up them throughout the AIs therapy and thereafter. Preliminary analysis of our data confirmed significant BMD loss in this group of patients. The AIs therapy influence on BMD loss was statistically significant after one year of therapy. For more valid data we need more patients and longer time of follow-up. Our plan is to continue in evaluation of influence of antiresorptive therapy on BMD as we observed trend of protection of BMD. Evaluation of importance of BMD loss for increase risk of pathological bone fractures also needs more patients and longer time of follow-up (Hadji et al., 2011).

Our observational study confirmed importance of BMD measurement and evaluation in postmenopausal early breast cancer patients on AIs therapy. This is in concordance with new recommendations for early breast cancer therapy published in July 2007 as a result of consensus conference (10 th St Gallen Conference) and other important international guidelines.

\section{Testicular cancer}

\subsection{Introduction}

Testicular cancer (TC) is still being serious disease although when the patients are correctly diagnosed and treated the cure rate is about $90 \%$. Testicular cancer make about $1 \%$ of malignant tumors in men, the incidence in recent years is going up. The incidence in Slovak Republic in 2003 was 7,3/100000 men and during last 30 years has increased almost 5times.TC appear mostly in men from 20 to 40 years of lilfe. (D. Ondruš \& M. Ondrušová, 2008). According to international classification more than $95 \%$ of TC are germ cell tumors (GCT), which are classified into two major subgroups: seminoma and non-seminoma GCT. Nonseminomatous GCT comprises approximately $50 \%$ of all GCT. Most tumors are mixed, consisting of two or more cell types (embryonal carcinoma, choriocarcinoma, yolk sac tumor, teratoma or their mixtures). The rest of testicular tumors are rare - Leydig cell tumors, Sertoli cell tumors, granulosa cell tumors, gonadoblastoma, sarcomas, lymphomas and others).

The diagnosis of GCT is based on clinical picture - painless testicular mass, symptoms of epididymitis or orchitis, less frequently occurs testicular pain.

For pretreatment staging we use ultrasound, computed tomography (CT) of chest, abdomen and pelvis and serum tumor markers (alfa-fetoprotein, human chorionic gonadotropin, lactate dehydrogenase).

The standard therapeutic procedure is surgery, radical orchciectomy and retroperitoneal lymph node dissection (according to histological type and stage of the disease). Other therapeutic options are radiotherapy and chemotherapy (again according to histological type and stage of the disease).

During recent decades the survival rate of patients with testicular cancer or germ cell tumors (GCT) has substantially improved. Consequently the long-term side effects of treatment of GCT have gained attention, including accelerated bone loss leading to increased risk of osteoporosis. Treatment-related bone loss is well recognized in breast and prostate cancer, but there has been little information in long-term survivors from other tumors (Marcus et al., 2008).

We have a large group of GCT patients in our registry at the Department of Urology of St. Elisabeth Cancer Institute with a long duration follow-up. It is already known that 
androgens influence bone modelling and remodelling acting on osteoblasts, osteocytes and pluripotent stem cells through androgen receptors. They also act indirectly via estrogen receptors. The combined influence of androgens and estrogens is even stronger. We suppose that patients after unilateral orchiectomy (OE) or bilateral orchiectomy and consecutive radiotherapy and/or chemotherapy should have lower levels of testosterone. Literature sources on this issue are scarce and conflicting. There are numerous animal studies proving the effect of androgens on bone and also proving much stronger effect of androgen and estrogen combination (Ondruš et al., 2007).

\subsection{Patients and methods}

Our aim was to determine BMD and serum bone turnover markers in survivors from GCT. We included 719 patients with GCT into the study. We measured BMD in GCT patients from 2005.

BMD was measured by dual-energy X-ray absorptiometry using osteodenzitometer Holgic Discovery in the lumbar spine and hips. BMD was classified as osteopenia (T score ranging from $-2,5$ to -1.0 ) and osteoporosis (T score less than -2. 5). Latter according to WHO recommendation for men under 50 years of age we use $\mathrm{Z}$ score (comparison of detected BMD to healthy bone of comparable age group).

C-terminal cross-linked telopeptides of type I collagen (CTX) were measured using EnzymeLinked Immunoabsorbent Assay (ELISA). Additionally serum total testosterone was measured.

Comparison was made with matched healthy control group from Ministery of health registry. Relationships between baseline characteristics (age, treatment type and time from orchiectomy) and BMD were assessed using univariate and multivariate analysis tools.

The data was evaluated using Microsoft Excel 2003 software and its built-in statistical functions and data analysis tools. We used standard uni-, bi- and multivariate statistical methods as appropriate throughout data analysis. Association between two nominal variables was tested using the Chi-squared test of independence. Association between an interval variable and a nominal one was tested using ANOVA or Kruskal-Wallis test, depending on the distribution of the interval variable; in case of a dichotomous variable, $\mathrm{t}$ test was applied instead of ANOVA and Mann-Whitney test instead of Kruskal-Wallis test. A multiple linear regression was performed to test for association between an dependent interval variable and several predicting interval variables (Mardiak et al., 2007)

\subsection{Results}

We included 719 patients into the study (21 - 76 yrs old, median: 39 yrs) who were treated for GCT since 1982. In this group, 663 pts (92\%) were treated by unilateral orchiectomy (OE) and 56 pts $(8 \%)$ by bilateral OE. The further treatment was radiotherapy of retroperitoneal lymph nodes (RPLND) in 124 pts (17\%), chemotherapy in 405 pts $(57 \%)$, radiotherapy and chemotherapy in in 16 pts (2\%), the rest 174 pts $(24 \%)$ did not receive any adjuvant therapy (fig. 7). Median time since OE was 6. 5 yrs, average time was 8.1 yrs.

We have proved a significant difference between BMD patients with GCT compared to the healthy population $(\mathrm{p}<0.0001)$ with more osteopenia and osteoporosis in GCT patients. 


\section{Patients with GCT: Sample Distribution According to Type of Orchiectomy}

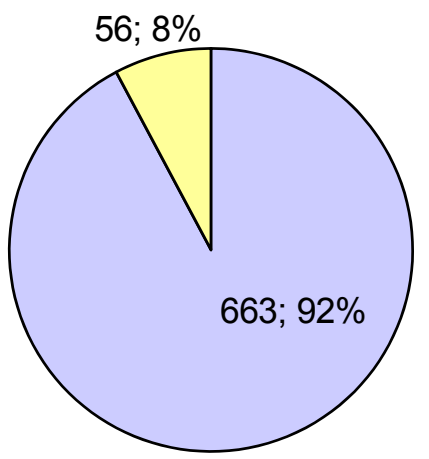

$\square$ Unilateral

$\square$ Bilateral

\section{Patients with GCT: Sample Distribution According to Therapy}

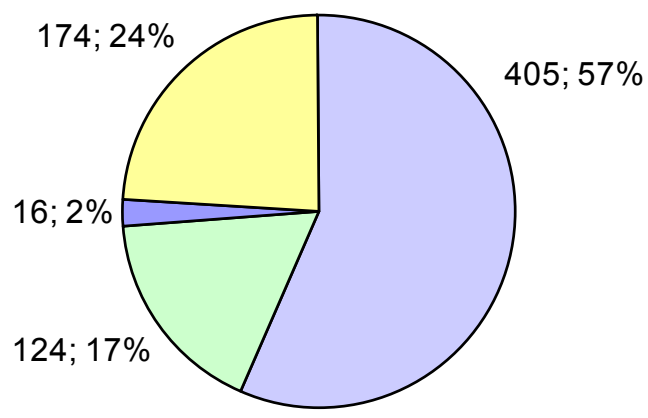

$\square$ Chemotherapy

$\square$ Radiotherapy

$\square \mathrm{CHT} / \mathrm{RAT}$

$\square$ Observation

Fig. 7. Patients characteristics

We have made comparisons between the group of GCT patients and the healthy match control group according to type of surgery and subsequent therapy (fig. 8) 
BMD in Patients with GCT Compared to Healthy Population

(isolated decrease in BMD not taken into account)

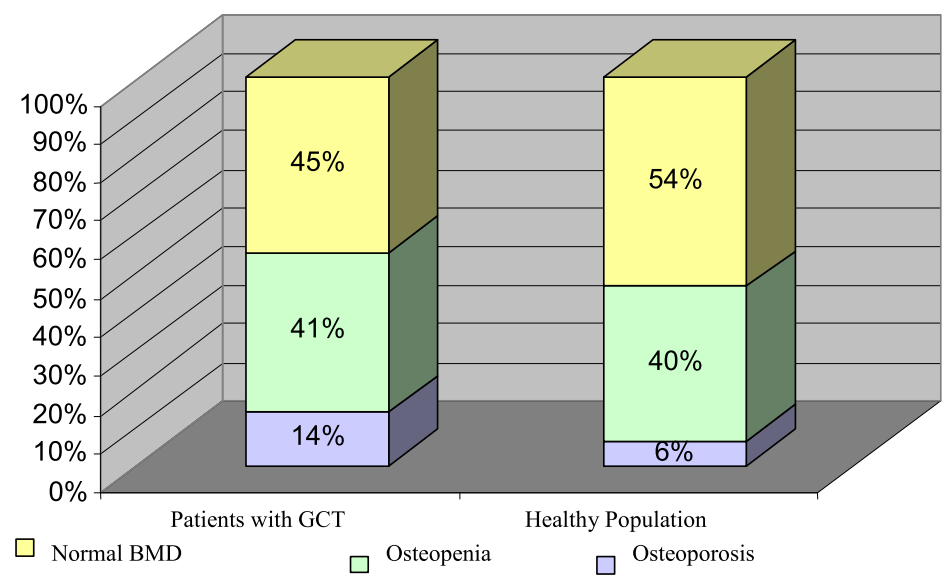

Fig. 8. Comparison of GCT group to healthy match control group

We made comparison of BMD and the type of orchiectomy (fg. 9)

\section{BMD and Type of Orchiectomy in Patients with GCT}

(isolated decrease in BMD not taken into account)

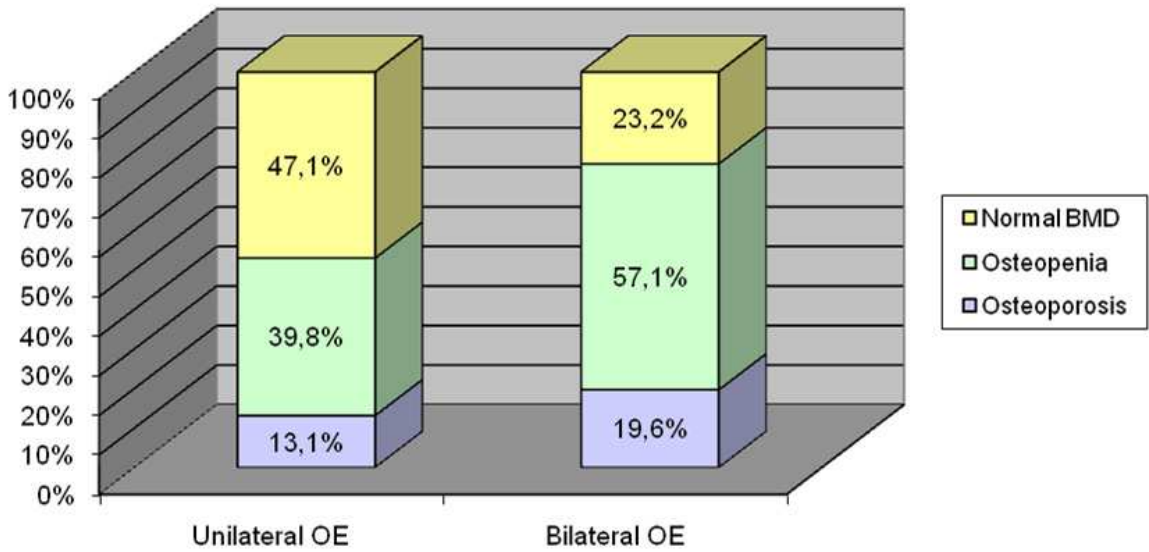

Fig. 9. Comparison of BMD and type of $\mathrm{OE}$

Comparison was made between the subgroup of patients with unilateral orchiectomy and a the subgroup of those treated with bilateral orchiectomy. While the incidence of osteoporosis has not proved to be significantly different in the two subgroups $(p=0.1725)$, patients treated with bilateral $\mathrm{OE}$ have significantly higher incidence of osteopenia $(\mathrm{p}=0.0116)$. 
We also made comparisons of BMD of patients with GCT and different types of OE to healthy match control group (fig. 10)

\section{BMD in Patients with GCT and Unilateral Orchiectomy} (isolated decrease in BMD not taken into account)

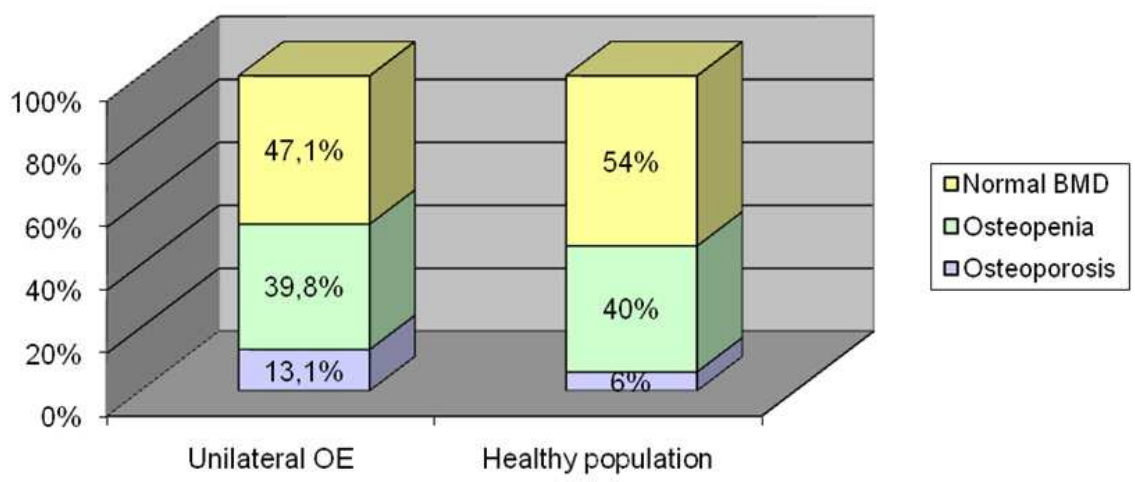

BMD in Patients with GCT and Bilateral Orchiectomy (isolated decrease in BMD not taken into account)

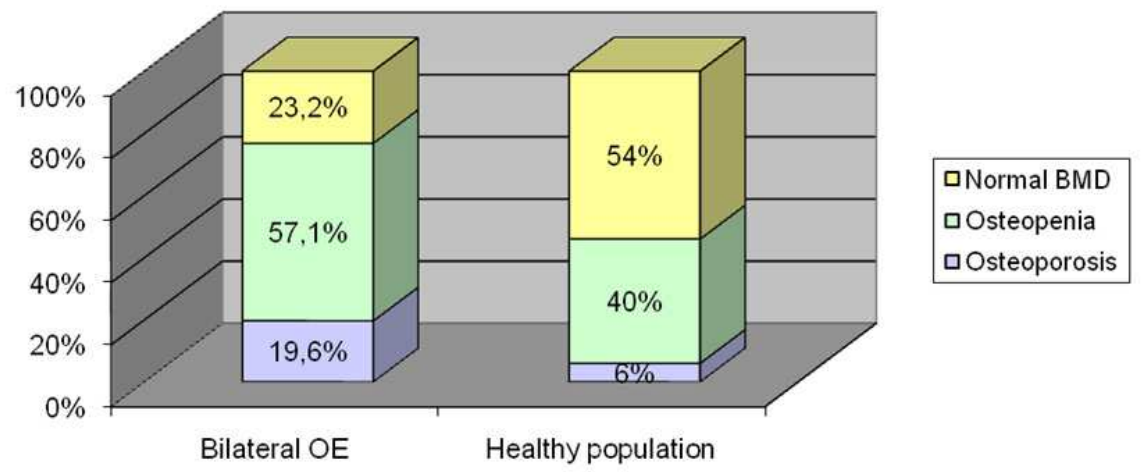

Fig. 10. Comparisons of BMD of patients with GCT and different types of OE to the healthy match control group

In a separate comparison of the subgroup of patients treated with bilateral orchiectomy to the healthy population we have concluded not only a significantly higher incidence of osteoporosis in the former $(\mathrm{p}<0.0001)$, but also a significantly higher incidence of osteopenia in those patients treated with bilateral OE $(p=0.0114)$. Patients treated with unilateral OE compared to the healthy population have a significantly higher incidence of osteoporosis $(\mathrm{p}<0.0001)$ We also made comparisons of BMD according to time from primary therapy 
BMD and Median Time since Orchiectomy in

Patients with GCT

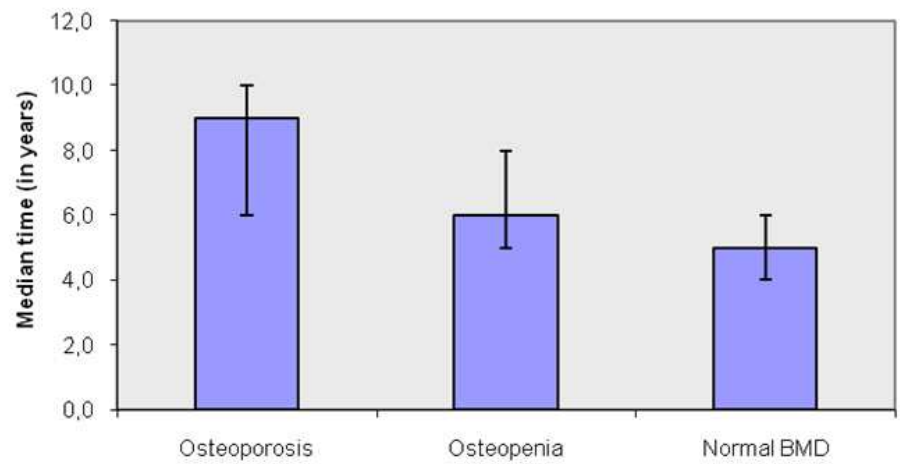

Fig. 11. BMD and median time since OE

All the most important results are summarized in table 2.

\begin{tabular}{|c|c|c|c|c|c|c|c|c|c|c|}
\hline & Total & Ost & eoporosis & & teopeni & & No1 & mal BI & $\mathrm{MD}$ & $P$ value \\
\hline Number of patients: & 719 & 98 & / $14 \%$ & 296 & / & $41 \%$ & 325 & / & $45 \%$ & \\
\hline $\begin{array}{l}\text { Treatment: } \\
\text { Unilateral OE } \\
\text { Bilateral OE } \\
\text { Chemotherapy } \\
\text { Radiotherapy } \\
\text { Chemo- and Radiotherapy }\end{array}$ & $\begin{array}{c}663 \\
56 \\
405 \\
124 \\
16\end{array}$ & $\begin{array}{c}87 \\
11 \\
48 \\
19 \\
3\end{array}$ & $\begin{array}{ll}/ & 13 \% \\
/ & 20 \% \\
/ & 12 \% \\
/ & 15 \% \\
/ & 19 \%\end{array}$ & $\begin{array}{c}264 \\
32 \\
172 \\
48 \\
10\end{array}$ & $\begin{array}{ll}1 & 4 \\
1 & 5 \\
1 & 4 \\
1 & 3 \\
1 & 6\end{array}$ & $\begin{array}{l}40 \% \\
57 \% \\
42 \% \\
39 \% \\
63 \%\end{array}$ & $\begin{array}{c}312 \\
13 \\
185 \\
57 \\
3\end{array}$ & $\begin{array}{l}1 \\
1 \\
1 \\
1 \\
1\end{array}$ & $\begin{array}{l}47 \% \\
23 \% \\
46 \% \\
46 \% \\
19 \%\end{array}$ & \\
\hline $\begin{array}{l}\text { Characteristics (Risk Factors): } \\
\text { Fractures } \\
\text { Demographics: } \\
\text { Median age } \\
\text { Average age }\end{array}$ & 98 & 10 & $\begin{array}{c}/ \quad 10 \% \\
43,0 \\
43,8\end{array}$ & 47 & $\begin{array}{c}/ \\
39,0 \\
39,5\end{array}$ & $48 \%$ & 41 & $\begin{array}{l}/ \\
37,0 \\
37,7\end{array}$ & & $\begin{array}{l}(<0.0001) \\
(<0.0001)\end{array}$ \\
\hline $\begin{array}{l}\text { Baseline Characteristics (medians): } \\
\text { Time since OE } \\
\text { Testosterone }(\mathrm{nmol} / \mathrm{l}) \\
\text { Free Testosterone }(\mathrm{pg} / \mathrm{ml}) \\
\text { CTX (scale 1: } \mathrm{ng} / \mathrm{ml}) \\
\text { CTX (scale 2: } \mathrm{pM}) \\
\text { LH }\end{array}$ & $\begin{array}{l}702 \\
478 \\
132 \\
137 \\
287\end{array}$ & & $\begin{array}{c}9,0 \\
16,8 \\
7,0 \\
0,4 \\
3341,0 \\
4,6\end{array}$ & & $\begin{array}{c}6,0 \\
16,6 \\
8,3 \\
0,5 \\
4175,5 \\
4,6\end{array}$ & & & $\begin{array}{c}5,0 \\
16,3 \\
8,3 \\
0,4 \\
3941,5 \\
4,6\end{array}$ & & $\begin{array}{l}(0.0049) \\
(0.6887) \\
(0.3526) \\
(0.5545) \\
(0.2101) \\
(0.3602)\end{array}$ \\
\hline
\end{tabular}

Table 2. Patients with GST - characteristics and results 


\subsection{Conclusions and future directions}

- We have proved a significant difference between BMD patients with GCT and healthy population $(\mathrm{p}<0.0001)$.

- The incidence of osteoporosis is significantly higher in patients with GCT compared to the healthy population $(\mathrm{p}<0.0001)$.

- While the incidence of osteoporosis has not proved to be significantly different in the two subgroups $(p=0.1725)$, patients treated with bilateral OE have significantly higher incidence of osteopenia $(\mathrm{p}=0.0116)$.

- Comparing the minimum T-score between the two subgroups, we have concluded significantly lower median T-score in patients with bilateral OE compared to those treated with unilateral OE $(\mathrm{p}=0.0148)$.

- We have come to the conclusion of no significant association between BMD and type of therapy in patients with GCT $(\mathrm{p}=0.287)$.

- There is no significant association between BMD and CTX level ( $p=0.1600)$.

- Correlation between T-score and testosterone also free testosterone level in patients with GCT, the correlation coefficient of 0.0881 , did not prove as significant $(\mathrm{p}=0.3263)$.

We did not find any significant differences between GCT and matched control data regarding the incidence of osteopenia and bone turnover marker, but the incidence of osteoporosis was considerably higher in GCT patients. The incidence of osteopororsis appeared to increase with age and to slightly correlate with time since OE, particularly after 10 years following OE. Type of therapy did not prove to have significant impact on the appearance of osteoporosis. Serum testosterone level did not correlate with BMD. We recommend BMD measurement and evaluation in GCT patients after therapy (Ondrušová et al., 2009).

\section{Bone mineral density in thyroid cancer (TC) patients on suppresive therapy after total thyroidectomy}

\subsection{Introduction}

Thyroid cancer (TC) is another type of cancer which should be associated with decrease of BMD after total thyreoidectomy and subsequent suppressive therapy. Although TC comprises only $1.1-1.9 \%$ of all cancers it is the most frequent endocrine tumor making around $90 \%$ of them. It is 3-times more frequent in women than in men. The most frequent types are well-differentiated cancers - papillary $(80-85 \%)$ and less frequent follicular (5 $10 \%)$ thyroid carcinoma.

The standard therapy of thyroid carcinomas (TC) consists of total or nearly total thyroidectomy. Then the whole-life substitution therapy by oral thyroxine $\left(\mathrm{T}_{4}\right)$ is given. Another goal of this therapy is to suppress serum thyroid stimulating hormone (TSH) to prevent the growth factor-like effect of TSH on well-differentiated TC cells. The recommendation is to administer supraphysiologic amounts of oral $T_{4}$. This leads to hyperthyroidism, which is subclinical. The influence of thyroid hormones on bone tissue is well known (Altabas et al., 2007). In hyperthyreosis the acitivty of osteoblasts and osteoclasts is increased, but the influence of osteoclasts is dominating leading to bone resorption and osteoporosis. The longstanding subclinical hyperthyroidism may result in 
increased bone turnover and decreased bone mineral density (BMD). The aim of the study was to assign the damage of bone metabolism in TC patients.

\subsection{Patients and methods}

Bone mineral density (BMD) was measured by dual energy photon x-ray absorptiometry BMD using osteodenzitometer Holgic Discovery in the lumbar spine and hips. In cases with arteficialy increased bone density caused by degenerative bone changes we measured BMD also in forearm. BMD was classified using $\mathrm{T}$ score in postmenopausal women and more than 50 years old men. We classified $\mathrm{Z}$ score in premenopausal women and younger than 50 years men. C-terminal cross -linked telopeptides of type I collagen (CTX) were measured using ELISA. Additionally serum TSH and $\mathrm{fT}_{4}$ (free $\mathrm{T}_{4}$ ) were measured. Relationships between baseline characteristics (age, menopausal status in women, TSH levels and duration of substitutional therapy) and BMD were assessed using univariate and multivariate analysis tools.

Association between two nominal variables was tested using the Chi-squared test of independence. Association between an interval variable and a nominal one was tested using ANOVA or Kruskal-Wallis test, depending on the distribution of the interval variable; in case of a dichotomous variable, t-test was applied instead of ANOVA and Mann-Whitney test instead of Kruskal-Wallis test. A multiple linear regression was performed to test for association between an dependent interval variable and several predicting interval variables.

We analysed BMD data from 165 TC patients after total tyroidectomy on supportive therapy in our study. There were 13 men and 152 women, 94 were postmenpausal (postMP), 44 premenopausal (preMP), in 14 the menopausal sattus was unknown. The mean age was 51 years. Age characteristics are in table 3.

\begin{tabular}{|l|c|c|c|c|}
\hline \multicolumn{5}{|c|}{ Age characteristics: } \\
\hline Min & All & Men & PostMP women & PreMP women \\
\hline Max & 21 & 29 & 34 & 21 \\
\hline Mean & 78 & 77 & 78 & 55 \\
\hline Median & 53 & 49 & 59 & 39 \\
\hline Standard deviation & 12.65 & 14.21 & 58 & 41 \\
\hline
\end{tabular}

Table 3. Age characteristics

\subsection{Results}

We included 165 TC patients in the study. There were 13 men a 152 women, the mean duration of thyroid suppressive therapy was 7.2 years $(0-24$ years). The patients exhibit osteporosis in 31\%, 39\% had osteopenia, whereas 30\% had normal BMD (fig. 12). 


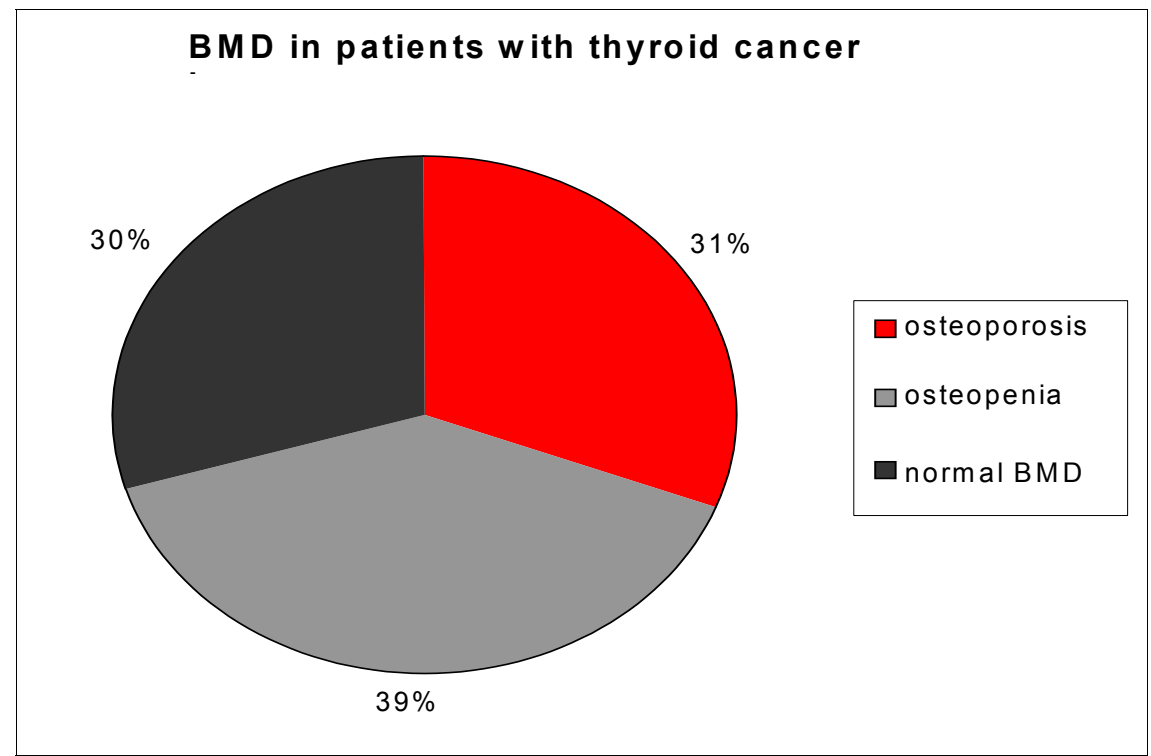

Fig. 12. BMD in TC patients

The BMD changes were localised in different sites (fig. 13)

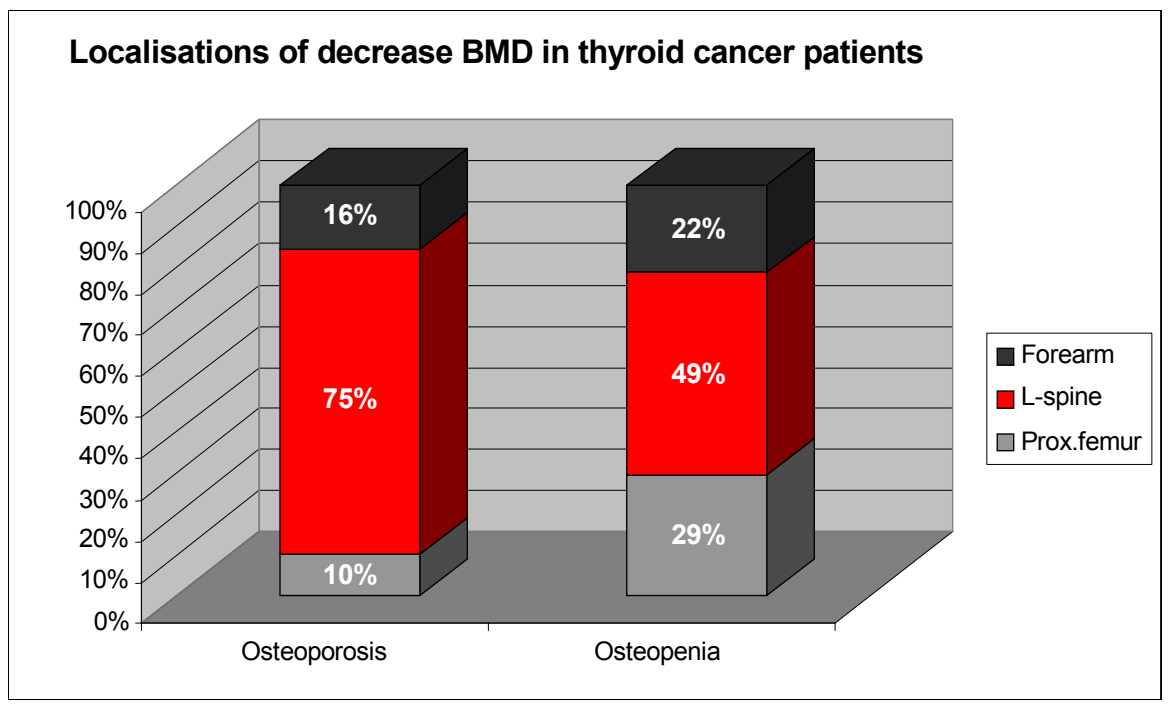

Fig. 13. Localisations of BMD decresae in TC paients

The incidence of osteoporosis appeared to increase with age but did not correlated with duration of thyroid suppressive therapy (fig. 14) 


\section{T-score and duration of suppressive therapy}

$$
r=0,1673(p=0,1458)
$$

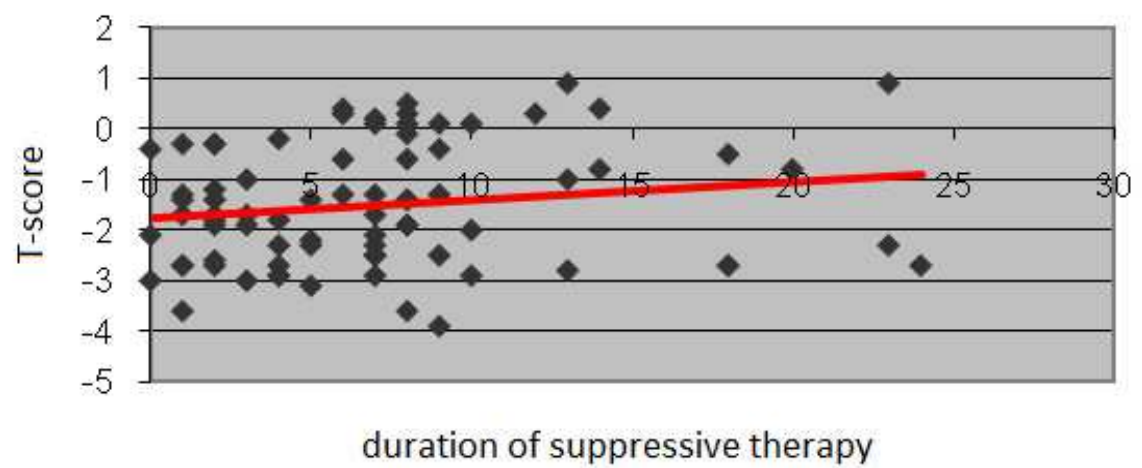

BMD and duration of suppressive therapy in TC patients $(p=0.2077)$

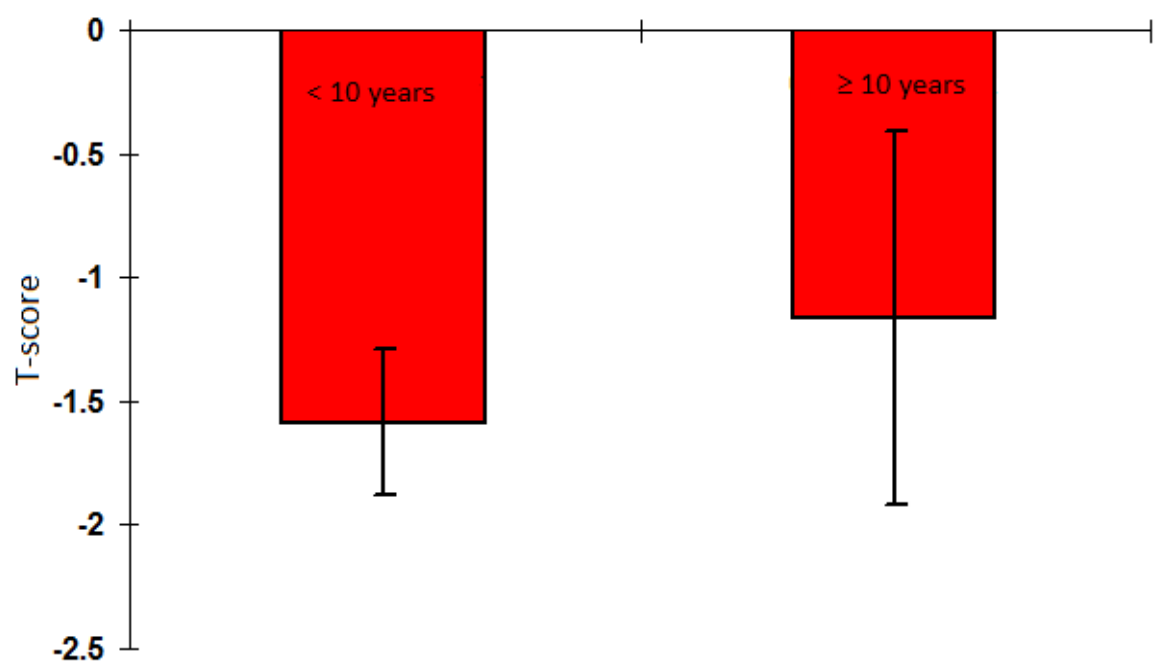

Fig. 14. Duration of suppressive therapy and BMD 
We confiirmed higher incidence of osteoporosis in postMP women and in the small subgroup of postMP women on antiporotic therapy we confirmed efficacy of this therapy (fig.15). But the gorup was very small and we cannot make any conclusuions.

\section{Comparison of BMD changes in controlled group of patients with/without antiresorptive therapy $(p=0.062)$}

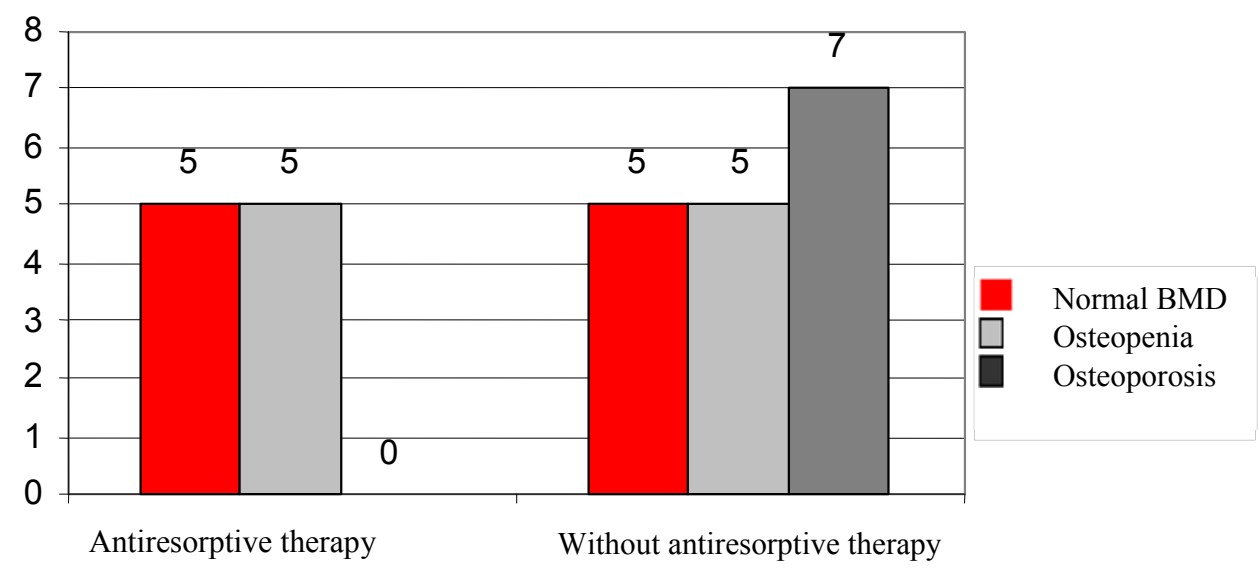

Fig. 15. Comparison of BMD changes in controlled group with/without antiresorpitve therapy

We confirmed 10 pathological fractures in our study (tab. 4)

Fractures

10 pathological fractures

Site

- wrist 3

- spine 3

- others 4

Table 4. Pathological fractures in TC patients

The pathological fractures were in correlation with decreased BMD to osteopenia or osteoporosis (fig. 16) 


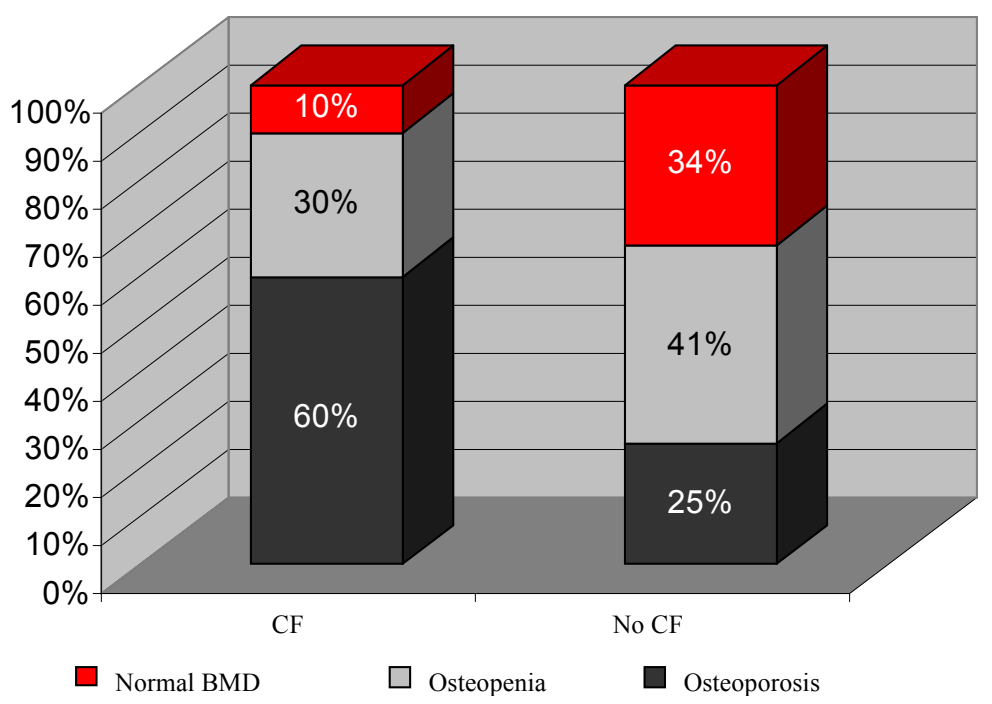

Fig. 16. BMD and compressive fractures in TC patients

\subsection{Discussion}

Published data on this topic are scarce and conflicting. Some of them did not prove correlation between subclinical hyperthyreosis and decrease in BMD (S. I. Greenspan \& F. S. Greenspan, 2005). Others have found, that if suppressive therapy does not suppress the TSH below normal value it does not decrease BMD and does not worsen the prognosis of TC (Biondi \& Cooper, 2010). Similar results were published also in the past (Shomon, 1995). Some on the other hand has confirmed that long term suppressive therapy affects bone turnover and bone mineral density in pre and postmenopausal women with TC (Heijekmann et al., 2005). Decrese in BMD as a result of suppressive therapy in TC was confirmed but this effect was ameliorated by preventive substitution of calcium and calcitonin (Mikosch et al., 2006). In this metaanalysis of 8 studies the influence of thyreoidal suppression on BMD in postmenopausal women was confirmed. It was not confirmed in men and premenopausal women. The limitation was a substantial inhomogeneity of patients groups and uneveness in calcium supplementation.

\subsection{Conclusions and future directions}

The long term survivors from TC after total thyroidectomy on thyroid suppressive therapy have higher risk of osteoporosis and therefore we recommend BMD testing and appropriate measures according to results. The BMD decrease may be a risk factor for pathological fractures and as the TC has very good prognosis, it does matter (B. Špániková.\& S. Špánik, 2011) 


\section{References}

Altabas, V., \& Berkovič, M., \& Bečejac, B., \& Solter, M.: Bone Remodeling and Thyroid Function, Acta Clin Croat 2007; 46: 41-47

Biondi, B., \& Cooper, D.S.: Benefits of thyreotropin suppresion versus the risk of adverse effects in differentiated thyroid cancer, Thyroid 2010; 20, 135-146.

Body, J. J. Increased Fracture Rate in Women With Breast Cancer: a Review of the Hidden Risk. BMC Cancer. 2011 Aug 29; 11 (1): 384. http:/ / www.biomedcentral.com/1471$2407 / 11 / 384$

Coates, A.S., \& Keshaviah, A., \& Thurlimann, B., et al.: Five years of letrozole compared with tamoxifen as initial adjuvant therapy for postmenopausal women with endocrine-responsive early breast cancer: update of study BIG 1-98, J Clin Oncol 2007; 25, 486-492

Coleman, R.E., \& Banks, L.M,, \& Girgis, S.I., \& Kilburn, L.S., \& Vrdoljak, E., \& Fox, J., \& Cawthorn, S.J., \& Patel, A., \& Snowdon, C.F., \& Hall, E., \& Bliss, J.M., \& Coombes, R.C.: Intergroup Exemestane Study group.Skeletal effects of exemestane on bonemineral density, bone biomarkers, and fracture incidence in postmenopausal women with early breast cancer participating in the Intergroup Exemestane Study (IES): a randomised controlled study, Lancet Oncol 2007 Feb:8(2),119-27

Coleman, R.E., \& Body, J. J., \& Gralow, Jr, Lipton A: Bone loss in patients with breast cancer receiving aromatase inhibitors and associated treatment strategies. Cancer Treat Rev 2008;34:S1-S18. July 2008

Coombes, R.C., \& Kilburn, L.S., \& Snowdon, C.F., et al. Survival and safety of exemestane versus tamoxifen after 2 - 3 years tamoxifen treatment (Inergroup Exmestane Study): a randomized controled trial. Lancet 2007; 369: 559 - 570.

Cooper, $\mathrm{C}$. The crippling consequences of fractures and their impact on quality of life. Am J Med 1997 Aug 18;103(2A):12S-17S; discussion 17S-19S.

Gnant M, et al.: Adjuvant ovarian suppression combined with tamoxifen or anastrozole, alone or in combination with zoledronic acid, in premenopausal women with hormone-responsive, stage I and II breast cancer: First efficacy results from ABCSG-12. ASCO 2008. Abstract LBA4

Goldhirsch, A., \& Wood, W.C., \& Gelber, R.D., \& Coates, A.S., \& Thurlimann, B., \& Senn, H.J, - Panel Members: Progress and promise: highlights of the internqational expert consensus on the primary therapy of early breast cancer 2007. Ann Oncol 2007; 18: $1133-1144$

Goos, P.E., \& Ingle, J.N., \& Martino, S., et al: Random.trial of letrozol tamoxifen as extended adjuvant therapy in receptor-positive breast cancer. Update findings from MA 17. J.Nat.Cancer Inst 2005; 97:1262-1271

Greenspan, S.I., \& Greenspan, F.S.: The effect of tyroid hormone on skeletal integrity. Horm Res 2005; 64(6), 293-8

Hadji, P., \& Aapro, M.S., \& Body, J.J.: Management of aromatase inhibitor-associated bone loss in postmenopausal women with breast cancer: practical guidance for prevention and treatement Annals of Oncol. Advance Access; 2011, doi:10.1093/annonc/mdr017 
Hadji, P \& Bundred, N.: Reducing the risk of cancer treatment-associated bone loss in patients with breast cancer. Semin Oncol 2007; Dec: 34 (6 Suppl 4): S4-10

Heijekmann, A.C., \& Huijberts, M.P., \& Geusens, P., \& Vries, J., \& Menheere, P., \& Wolffenbuttel, B.: Hip bone mineral density, bone turnover and risk of fracture in patiens on long-term suúúressive L-thyroxine therapy for differentiared toroid carcinoma Eur J Endocrinol 2005; 153, $23-29$

Howell, A., \& Cuzick, J., \& Baum, M., \& Buzdar, A., \& Dowsett, M., \& Forbes, J.F., \& HoctinBoes, G., \& Houghton, J., \& Locker, G.Y., \& Tobias, J.: Results of the ATAC (Arimidex, Tamoxifen, Alone or in Combination) trial after completion of 5 years' adjuvant treatment for breast cancer. Lancet. 2005 Jan 1-7;365 (9453), 60-2.

Jakesz, R., et al: Switching of postmenopausal women with endocrine-responsive early beast cancer to anastrozole after two years adjuvant tamoxifen: Combine results of ABCSG trial 8 and ARNO 95 trial. Lancet 2005;366: 455 - 462

Kanis, J. A., \& Johnell, O., \& Oden,.A., \& Johansson, H., \& Closkey, E.Mc.: Frax ${ }^{\mathrm{TM}}$ and the assessment of fracture probability in men and women from the UK. Osteoporos Int. 2008; 19, s. 385-397

Marcus, R., \& Feldman, D., \& Nelson, D.A., \& Rosen, C.J.: Osteoporosis, Elsevier AP, Burlington MA, 2008: 1939

Mardiak, J., \& Ondrus, D., \& Spanikova, B., \& Ostatnikova, B.: Damage of bone metabolism and osteoporosis in testicular cancer patients. J Clin Oncol (Meeting Abstracts) June 2007 vol. 25 no. 18_suppl 5052

Mikosch, P., \& Igerc, I., \& Kudlacek, S., \& Woloszczuk, W., \& Kresnik, H., et al: Receptor activator of nuclear factor kappa B ligand and osteoprotegerin in men with thyroid cancer. Eur J Clin Invest 2006; 36, 8, 566-73

Ondruš, D., \& Ondrušová, M.: Testicular cancer - diagnostic and therapy. Onkológia 2008; 3 (3): 170-174

Ondruš, D., \& Špániková, B., \& Ondrušová, M., \& Mardiak, J.: Damage of hormonal function and bone metabolism in long term survivors of testicular cancer. European Andrology, 2007; 1,1, 36-37

Ondruš, D., \& Špániková, B., \& Ondrušová, M., \& Mardiak, J.: Testosteron deficiency and bone metabolism damage in testicular cancer survivors. Urology 2007; 70, 3A, 166

Ondrušová, M., \& Ondruš, D., \& Dušek, L., \& Špániková, B.: Damage of hormonal function and bone metabolism in long -terma survivors of testicular cancer. Neoplasma $2009 ; 56,6473-479$

Payer, J., \& Rovensky, J., \& Killinger, Z. Lexikon of osteoporosis. Slovak Academic Press 2007; Bratislava, 75 pp., ISBN: 80809

Rizzoli, R, \& el. Atlas of postmenopausal osteoporosis. 2nd ed. London: Current Medicine Group, 2005:25-46.

Shomon, M.: The tyroid treatement osteoporosis Controversy. Does the tyroid treatement contribute to los soft bone density? Thyroid 1995; 5(1):13-7

Špánik, S., \& Špániková, B.: Bone mineral density in early brest cancer patients. Bratisl Lek Listy 2010; 111(1) 27-32

Špániková, B., \& Špánik, S.: Changes in bone mineral density in breast cancer patients. Osteolog bulletin 2010; 15,3,127-8 
Špániková, B., \& Špánik, S.: Bone mineral density in patients with thyroid cancer on suppressive therapy after total thyroidectomy. J Clin Oncol 29:2011 (suppl; abstr e 19739)

Thürlimann, B., \& Keshaviah, A., \& Coates, A.S., \& Mouridsen, H., \& Mauriac, L., \& Forbes, J.F., \& Paridaens, R., \& Castiglione-Gertsch, M., \& Gelber, R.D., \& Rabaglio, M., \& Smith, I., \& Wardley, A., \& Price, K.N., \& Goldhirsch, A.: Breast International Group (BIG) 1-98 Collaborative Group, A comparison of letrozole and tamoxifen in postmenopausal women with early breast cancer .N Engl J Med. 2005; Dec 29, 353(26), 2747-57 


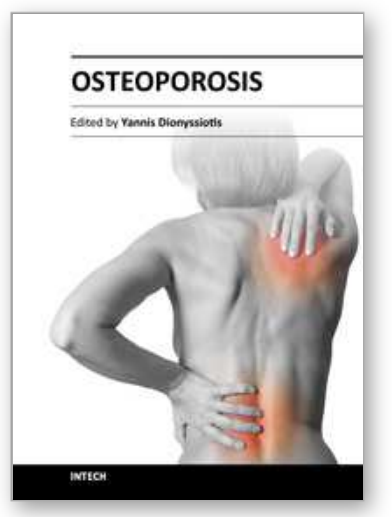

\author{
Osteoporosis \\ Edited by PhD. Yannis Dionyssiotis
}

ISBN 978-953-51-0026-3

Hard cover, 864 pages

Publisher InTech

Published online 24, February, 2012

Published in print edition February, 2012

Osteoporosis is a public health issue worldwide. During the last few years, progress has been made concerning the knowledge of the pathophysiological mechanism of the disease. Sophisticated technologies have added important information in bone mineral density measurements and, additionally, geometrical and mechanical properties of bone. New bone indices have been developed from biochemical and hormonal measurements in order to investigate bone metabolism. Although it is clear that drugs are an essential element of the therapy, beyond medication there are other interventions in the management of the disease. Prevention of osteoporosis starts in young ages and continues during aging in order to prevent fractures associated with impaired quality of life, physical decline, mortality, and high cost for the health system. A number of different specialties are holding the scientific knowledge in osteoporosis. For this reason, we have collected papers from scientific departments all over the world for this book. The book includes up-to-date information about basics of bones, epidemiological data, diagnosis and assessment of osteoporosis, secondary osteoporosis, pediatric issues, prevention and treatment strategies, and research papers from osteoporotic fields.

\title{
How to reference
}

In order to correctly reference this scholarly work, feel free to copy and paste the following:

Beata Spanikova and Stanislav Spanik (2012). Studies of Osteoporosis in Cancer Patients in Slovakia Experience from Single Institute, Osteoporosis, PhD. Yannis Dionyssiotis (Ed.), ISBN: 978-953-51-0026-3, InTech, Available from: http://www.intechopen.com/books/osteoporosis/studies-of-osteoporosis-in-cancerpatients-in-slovakia-experience-from-single-institute

\section{INTECH}

open science | open minds

\section{InTech Europe}

University Campus STeP Ri

Slavka Krautzeka 83/A

51000 Rijeka, Croatia

Phone: +385 (51) 770447

Fax: +385 (51) 686166

www.intechopen.com

\section{InTech China}

Unit 405, Office Block, Hotel Equatorial Shanghai

No.65, Yan An Road (West), Shanghai, 200040, China

中国上海市延安西路65号上海国际贵都大饭店办公楼 405 单元

Phone: $+86-21-62489820$

Fax: +86-21-62489821 
(C) 2012 The Author(s). Licensee IntechOpen. This is an open access article distributed under the terms of the Creative Commons Attribution 3.0 License, which permits unrestricted use, distribution, and reproduction in any medium, provided the original work is properly cited. 